\title{
The effects of order of shock durations on helplessness in rats
}

\author{
TASHA PRABHAKAR and R. F. SOAMES JOB \\ University of Sydney, Sydney, New South Wales, Australia
}

\begin{abstract}
Whereas rats exposed to a series of progressively decreasing shock durations show deficits in shuttleescape performance $24 \mathrm{~h}$ later, the same number and intensity of shocks in the reverse (increasing) order of durations does not produce the "learned helplessness" effect (Balleine \& Job, 1991). We conducted two experiments to establish the generality of this shock-duration order effect on other measures of distress and helplessness in rats. In Experiment 1, rats exposed to decreasing durations of inescapable shock showed reduced consumption of quinine-adulterated water (finickiness), whereas increasing durations produced no finickiness. By contrast, increasing shock durations produced greater conditioned fear to the shock context than did decreasing shock durations in Experiment 2. The differential effects of shock-duration order on finickiness and fear are explicated in terms of the specificity of fear conditioning during exposure to increasing versus decreasing series of shock duration orders.
\end{abstract}

Animals exposed to uncontrollable (inescapable) electric shock frequently show subsequently retarded escape and avoidance learning when compared with subjects receiving prior controllable (escapable) shock or simple apparatus exposure (Brown \& Dixon, 1983; Job, 1987; Maier, 1970; Overmier \& Seligman, 1967; Rosellini, DeCola, Plonsky, Warren, \& Stillman, 1984). The occurrence of this learned helplessness effect is influenced by a variety of parameters associated with the schedule of uncontrollable shock used during stress pretreatment, including shock intensity and duration (Glazer \& Weiss, 1976a; Jackson, Maier, \& Rapaport, 1978; Rosellini \& Seligman, 1978; Steenbergen, Heinsbroek, Van Haaren, \& Van de Poll, 1989), current characteristics (Crowell, Lupo, Cunningham, \& Anderson, 1978), the minimum intertrial interval (Minor, Trauner, Lee, \& Dess, 1990; Rosellini, DeCola, \& Warren, 1986), and the ability to predict shock termination or shock-free periods (Jackson \& Minor, 1988; Minor et al., 1990; Overmier \& Murison, 1989). A number of studies also suggest that the ordering of shock durations across pretreatment trials is an important determinant of the helplessness effect.

In the traditional triadic design, shock durations generally decrease across trials during the pretreatment session as the master subject becomes increasingly efficient at executing the escape response (cf. Jackson \& Minor, 1988; Job \& Barnes, 1995; Minor \& LoLordo, 1984). Subjects receiving yoked inescapable shock under these conditions usually show severe impairment of shuttle-escape learning $24 \mathrm{~h}$ later. This helplessness effect also is observed fol-

This research was supported in part by a Sydney University Research Grant and an Australian Research Council Grant to R.F.S.J. Reprint requests should be directed to T. Prabhakar, Department of Psychology, Sydney University, New South Wales 2006, Australia (e-mail: tashap@)psychvax.psych.su.oz).

-Accepted by previous editor, Vincent M. LoLordo lowing preexposure to fixed-duration or randomly ordered variable-duration inescapable shocks (see, e.g., Glazer \& Weiss, 1976a; Minor et al., 1990; Warren, Rosellini, \& Plonsky, 1985).

By contrast, deficits in test escape performance do not occur when rats are exposed to a series of inescapable shocks that generally or specifically increase in duration across the pretreatment stress session. Anderson and his colleagues (Anderson, Crowell, Cunningham, \& Lupo, 1979; Crowell \& Anderson, 1979; Crowell et al., 1978) and Nation and Matheny (1980) progressively increased the criterion duration during which master rats had to maintain an inactive posture in order to terminate shock during stress pretreatment. As a consequence of this feature of the escape contingency, yoked subjects were likely to have received a series of inescapable shocks that generally increased in duration across the session. Yoked subjects failed to show the traditional helplessness effect during later testing under these conditions. More recently, Balleine and Job (1988) replicated this finding and linked the presence or absence of behavioral impairment to the specific ordering of inescapableshock durations during pretreatment. The escape latencies of a master rat were reordered into either a progressively increasing or a progressively decreasing series of inescapableshock durations, or were left unchanged. Whereas preexposure to the unaltered or decreasing series of shock durations produced the traditional deficit in escape performance $24 \mathrm{~h}$ later, no escape deficit resulted from earlier experience with the increasing series. This phenomenon is termed the shock-duration order effect.

Balleine and Job (1991) argued that the shock-duration order effect can be accommodated by a variation of the competing-response explanation for helplessness effects (Anisman \& Waller, 1973; Bracewell \& Black, 1974; Glazer \& Weiss, 1976a, 1976b; Levis, 1976). The onset of inescapable shock initially produces a burst of activity that lasts 3-4 sec, which is followed by a passive reaction (freez- 
ing) that remains until shock terminates on a trial (Anisman, deCantanzaro, \& Remington, 1978; Glazer \& Weiss, 1976b; Jackson, Maier, \& Rapaport, 1978). Thus, when shock durations are comparatively long early in the stress session, freezing is very likely to co-occur with shock termination. Shock termination may adventitiously reinforce the freezing pattern, thus increasing its probability and duration as a reaction to shock. If shock durations decrease across trials, the freezing response may be further strengthened by a decrease in the delay of reinforcement such that it becomes a generalized response to shock which transfers to later testing. Because the escape tasks typically used to assess helplessness require an active response to shock, animals with a preconditioned tendency to be inactive or freeze in response to shock should perform poorly. Exactly the opposite may occur when shock durations are comparatively short early in training and progressively increase across the pretreatment session. The initial activity burst in response to shock may be strengthened by shock termination early in training. This predisposition for an active response to shock may be strengthened further by a partial reinforcement effect as shock duration gradually increases over the stress session. Alternatively, initial strengthening of activity may simply preclude the subsequent conditioning of inactivity. In either case, animals entering the test phase without a strong tendency to be inactive in the presence of shock should fare much better in tasks that require active responding.

In the present paper, we present two experiments that were designed to assess the shock-duration order effect further. The competing-response hypothesis discussed above suggests that a differential effect of exposing rats to an increasing or a decreasing series of inescapable-shock durations during pretreatment should be observed only in test tasks that require high levels of activity in the presence of shock for successful performance. The shock-duration order effect should not be observed in test tasks that do not involve reexposure to shock and require low levels of activity. Thus, in Experiment 1 , we examined the effect of shock-duration order during pretreatment on bitter-taste finickiness in rats, a test measure of distress and helplessness that does not involve reexposure to shock and does not require sustained, highlevel activity (Dess, 1991; Dess \& Chapman, 1990; Dess, Chapman, \& Minor, 1988; Job \& Barnes, 1995; Prabhakar \& Job, 1994). In Experiment 2, we directly observed freezing behavior during and following exposure to an increasing or a decreasing series of inescapable-shock durations to directly assess the validity of some of the main assumptions of the competing-response hypothesis.

\section{EXPERIMENT 1}

Exposure to uncontrollable shock produces a cluster of effects on ingestion, digestion, and metabolism, including stomach mucosal injury (Garrick, Minor, Bauck, Weiner, \& Guth, 1989; Overmier \& Murison, 1989; Weiss, 1968, 1971a), changes in plasma cholesterol (Berger, Starzec, Mason, \& DeVito, 1980) even in the absence of a high fat or high cholesterol diet (Brennan, Job, Watkins, \& Maier, 1992), and body weight loss (Brennan et al., 1992; Dess, 1991; Dess, Raizer, Chapman, \& Garcia, 1988; Kelsey, 1977; Weiss, 1971a, 1971b, 1971c). In addition, inescapable shock affects primary gustation, which is typified by finicky consumption of bitter-tasting food or water (Brush et al., 1988; Dess, 1991; Dess \& Chapman, 1990; Dess, Chapman, \& Minor, 1988; Job \& Barnes, 1995; Prabhakar \& Job, 1994). The finickiness effect appears to be well suited for testing the generality of the shock-duration order effect and assessing the viability of the competing response explanation. This index of distress and helplessness is conducted in the rat's home cage, does not involve reexposure to shock, and does not require sustained, high-level activity. Thus, if the effect of shock-duration order on later escape performance is due to the differential conditioning and transfer of freezing behavior, which competes with active responses to shock in the decreasing-duration group, then an effect of shock-duration order should not be observed with the finickiness measure.

\section{Method}

Subjects. Thirty experimentally naive male Wistar rats weighing between 244 and $505 \mathrm{~g}$ were housed individually with free access to food and water in a room maintained on a 12:12-h light:dark cycle, with light beginning at $0700 \mathrm{~h}$.

Apparatus. Fluids were presented in the home cages in $600-\mathrm{ml}$ bottles with stainless steel spouts. The quinine solution was $5.2 \mathrm{mg} / \mathrm{L}$ of quinine sulfate (Australia Chemical Co) in tap water.

The stress session was administered in six operant chambers $25 \mathrm{~cm}$ long $\times 29 \mathrm{~cm}$ wide. Half of the boxes measured $24 \mathrm{~cm}$ in height and the other half of the boxes were $45 \mathrm{~cm}$ in height. The two sidewalls were constructed of aluminum, and the ceiling, back wall, and door were of clear Plexiglas. The floor consisted of stainless steel rods $(5 \mathrm{~mm}$ in diameter) spaced $1.5 \mathrm{~cm}$ apart center to center. Shock was delivered to the grid floor using R. S. Hales shock generators and scramblers. The shock generators were calibrated via a variable resistor to supply alternating current at a peak-to-peak value of $0.6 \mathrm{~mA}$. Shock was scrambled at a frequency of $50 \mathrm{~Hz}$ with a duty cycle of $31.5 \%$.

Each pretreatment apparatus was located in a black soundattenuation chamber $(64 \times 62 \times 64 \mathrm{~cm})$. A $2-\mathrm{W}$ light on the rear wall of the chamber and light from a $25 \mathrm{~cm} \times 10 \mathrm{~cm}$ observation window of the chamber provided the only illumination. A fan housed in the rear wall of the attenuation chamber provided air circulation and masking noise at $64 \mathrm{~dB}$ SPL.

Procedure. We maintained rats on a restricted drinking schedule throughout the experiment in which fluid was available for $8 \mathrm{~min}$ at $1200 \mathrm{~h}$, followed by $30 \mathrm{~min}$ of availability at $1600 \mathrm{~h}$. Tap water was presented during the prestress baseline phase, which lasted 11 days prior to stress treatments. Rats were handled on Days 1-5 for 5 min before drinking.

The stress session was conducted at $0800 \mathrm{~h}$ on Day 12 . Rats were assigned randomly to one of three groups of 10 rats each and received: (1) decreasing durations of unsignaled inescapable shock (D-IS); (2) increasing durations of unsignaled inescapable shock (I-IS); or (3) no shock (C-NS). The programmed shock sequences were obtained from previously recorded latencies of a rat exposed to escapable shock in Balleine and Job (1991, Experiment 2). This sequence of unsignaled shock durations was reordered into a continuously decreasing or continuously increasing order over 110 trials (average duration $=15.65 \mathrm{sec}$; range: $3-38 \mathrm{sec}$ ).

Each trial was nominally $60 \mathrm{sec}$ in duration: When shock terminated on a trial, an additional time period elapsed before the ITI commenced, so that the shock duration on a trial plus the additional 
elapsed interval was equal to $60 \mathrm{sec}$. The ITIs averaged $45 \mathrm{sec}$ (range, 30-60 sec). This aspect of the protocol resulted in an actual interval between shocks that averaged $89 \mathrm{sec}$.

On the 3 days following the day of the stress treatment, rats were given $8 \mathrm{~min}$ of access to quinine solutions in their home cages beginning at $1200 \mathrm{~h}$, followed by $30 \mathrm{~min}$ of access to water at $1600 \mathrm{~h}$.

Statistical analysis. Alpha was set at .05 for all statistical tests. We used planned contrasts to examine directional predictions regarding quinine consumption and suppression data, which were based on our previous work on the shock-duration order effect. Because no such explicit predictions were made for water consumption, an analysis of variance (ANOVA) was used to assess any group differences on this measure.

\section{Results and Discussion}

A measure of test drinking relative to the previously established baseline (cf. Dess \& Chapman, 1990; Dess, Chapman, \& Minor, 1988) was not possible, because fluid consumption increased significantly across days of the experiment $[F(2,30)=17.54, p<.001]$. Consequently, the effect of stress on test quinine ingestion was assessed in terms of (1) the absolute volume of quinine-adulterated water consumed, and (2) quinine consumption relative to water intake during the 30 -min drinking session on each test day.

The mean absolute volume of quinine consumed over the 3 test days in each of the three groups is shown in Figure 1. Quinine finickiness was evident in Group D-IS, but not in Group I-IS, relative to the no-shock control group (C-NS). A planned (one-tailed) contrast of absolute consumption averaged over the 3 test days indicated that Group D-IS drank significantly less quinine than did Group C-NS $[t(18)=3.19, p=.005]$. Importantly, poststress quinine intake in Group D-IS also was suppressed relative to the other inescapably shocked group I-IS $[t(18)=3.73, p=.001$, one-tailed $]$. Finally, Groups I-IS and C-NS did not differ significantly in quinine drinking $[t(18)=0.23, p=.820$, two-tailed], indicating that there was no interference with ingestive behavior in the group

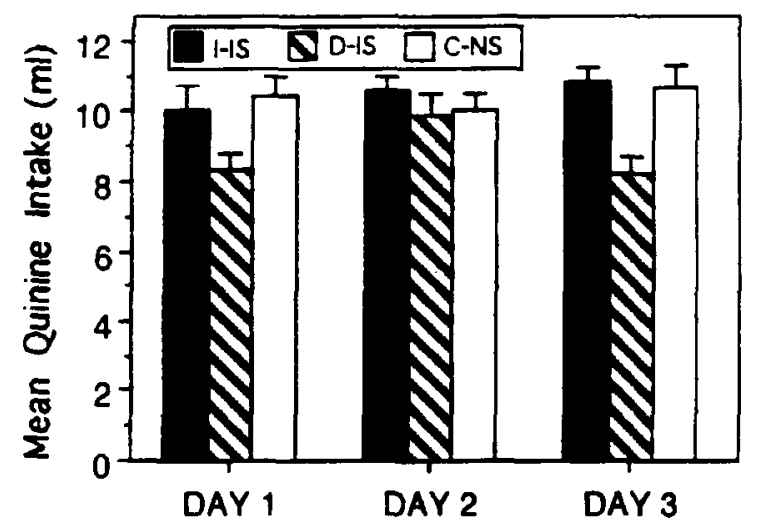

Figure 1. The mean absolute amount of quinine consumed across the three test sessions in each of three groups. Rats were exposed to a series of increasing inescapable-shock durations (Group I-IS), a series of decreasing shock durations (Group D-IS), or no shocks (Group C-NS) and then tested for quinine ingestion 24, 48, and $72 \mathrm{~h}$ after the stress session. Each test session began at $1200 \mathrm{~h}$. that had received earlier exposure to an increasing series of inescapable shock durations. A mixed-design ANOVA (group $\times$ day) yielded no main effect of day $[F(2,54)<1]$ and no group $\times$ day interaction $[F(4,54)=1.61, p=.186]$, indicating that the group effects described above continued over the 3 test days.

Figure 2 shows test quinine consumption as a percentage of the water baseline on each test day for all three groups. The same pattern among groups that occurred for absolute quinine intake also occurred for the relative measure. Planned contrasts indicated that finickiness occurred in Group D-IS relative to Group C-NS $[t(18)=1.92, p=$ .0355 , one-tailed]. D-IS rats also were more finicky than I-IS rats $[t(18)=2.24, p=.038$, two-tailed]. A mixeddesign ANOVA (group $\times$ day) yielded neither a main effect of day $[F(2,54)=1.27, p=.307]$ nor a group $\times$ day interaction $(F<1)$.

The amount of water consumed during the 30 -min session conducted at $1600 \mathrm{~h}$ is shown in Figure 3. Similar water consumption occurred in all three groups. Separate one-way ANOVAs of group data yielded no significant difference in water consumption on Days 1,2 , or $3(F \mathrm{~s}<1)$. Because Group D-IS suppressed consumption of quinine-adulterated water during the earlier test period (at $1200 \mathrm{~h}$ ), the similarity among groups in water consumption at $1600 \mathrm{~h}$ suggests that incomplete compensatory drinking occurred in the D-IS group.

This experiment replicates the finding of reduced ingestion of a bitter-tasting fluid following exposure to unsignaled inescapable shock (Dess \& Chapman, 1990; Dess, Chapman, \& Minor, 1988). More importantly, the occurrence of this finickiness effect was modulated by the manner in which inescapable-shock durations were ordered during stress pretreatment. Whereas a systematic decrease in the duration of inescapable shock across the stress session provoked substantial finickiness (Group D-IS), an increasing order of shock durations did not (Group I-IS).

These data indicate that the effects of shock-duration order are relevant to interference phenomena other than escape behavior (Balleine \& Job, 1991). Therefore these results present a problem for the response-competition hypothesis account of the shock-duration order effect (Balleine \& Job, 1991). Whereas the differential conditioning of competing responses during D-IS treatment is a plausible explanation for the excessive retardation of later escape performance in D-IS animals, response competition is less likely to influence the finickiness test, which involves simple home-cage drinking. Thus, the responsecompetition explanation does not appear to provide a parsimonious account of the present results.

A post hoc account of the finickiness data may be offered in terms consistent with the anxiety hypothesis. According to the anxiety account, helplessness effects are produced by the more substantial and chronic fear engendered by unsignaled inescapable shock compared with escapable or predictable shock (Minor et al., 1991). Given this explanatory mechanism, the anxiety hypothesis could accommodate the present results and those of Balleine and Job $(1988,1991)$ if D-IS treatment produced more chronic 


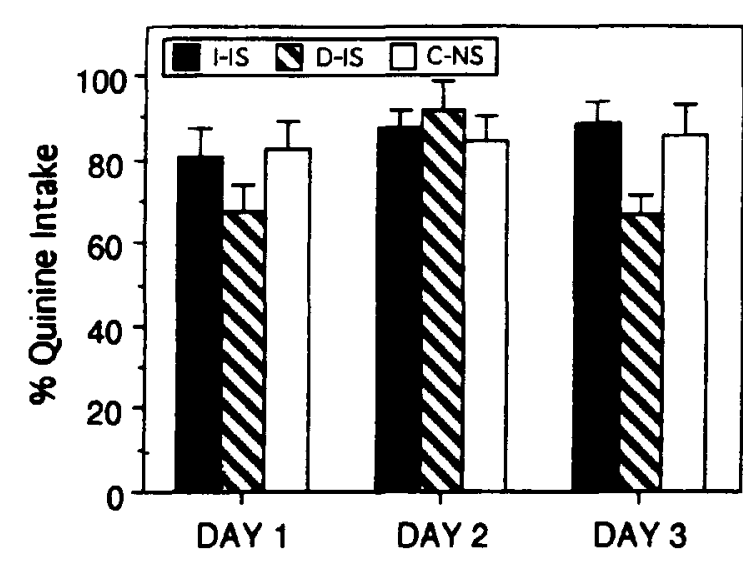

Figure 2. Mean suppression (\%) of quinine drinking during the sessions of Test Days 1, 2, and 3 at $1200 \mathrm{~h}$ in each of the three groups. The amount of quinine consumed is expressed as a percentage of the amount of water consumed on the same day. Rats were exposed to a series of increasing inescapable-shock durations (Group I-IS), a series of decreasing shock durations (Group D-IS), or no shocks (C-NS).

fear during pretreatment than did I-IS treatment. Although the mechanism(s) by which shock-duration order influences the level of fear is not clear, the simple relation between the two variables is directly testable.

\section{EXPERIMENT 2}

We tested the post hoc explanation of the shock-duration order effect in terms of differential levels of fear in Experiment 2. The correspondence between helplessness effects and fear within the anxiety hypothesis allows the prediction that the increasing duration group should exhibit less fear in response to the shock context than should the decreasing duration order group. Therefore fear $24 \mathrm{~h}$ after shock was measured in Experiment 2.

The results of Experiment 1 also suggest that there may be problems for the response competition explanation of shock-duration order effects. This account was examined further in Experiment 2. If the activity account given by this hypothesis is viable, rats exposed to decreasing shock durations should show a greater increase in freezing over trials during the stress session than should subjects exposed to the increasing shock-duration order. Therefore, Experiment 2 also included a comparison of the amount of freezing behavior across trials for the entire shock session.

\section{Method}

Subjects. Thirty experimentally naive male Wistar rats were housed as in Experiment 1. Food and water were freely available throughout the experiment.

Apparatus. The apparatus for the stress session (Phase 2) was identical to that used in Experiment 1.

An operant box identical to that used for the stress session was modified for the preexposure and fear test phases of the experiment. The back wall of the box was removed, and an adjoining chamber $(25 \times 29 \times 45 \mathrm{~cm})$ with a wooden "safety" platform floor was attached. The wooden floor was $1.5 \mathrm{~cm}$ above the level of the grid floor in the first chamber. A clear Plexiglas door was positioned between the chamber with the grid floor and the chamber with the safety floor. The chamber with the safety platform was also distinguished by the addition of black and white check print that covered the inside walls. The door between the chambers could be lifted, allowing a rat to move freely between chambers through a $29 \times 25 \mathrm{~cm}$ opening. The modified box was located in a black sound-attenuation chamber, measuring $64 \times 62 \mathrm{~cm} \times 64 \mathrm{~cm}$.

Procedure. The experiment consisted of three phases: (1) preexposure, (2) stress session, and (3) fear test.

Preexposure was conducted on Day 1 of the experiment. Each rat was placed on the wooden safety platform in the modified operant box for $15 \mathrm{~min}$ (cf. Rosellini et al., 1986). The door to the soundattenuation chamber was open for similarity to the test stage, in which the door was open for the purpose of observation. The room was illuminated by light from a window. The rats were returned to their home cages immediately after preexposure.

On Day 2, the rats were assigned randomly to one of the three groups of 10 rats each and exposed in the stress chambers to (1) the decreasing order of inescapable-shock durations (Group D-IS); (2) the increasing order of inescapable-shock durations (Group I-IS); or (3) no shock (Group C-NS). All aspects of the stress treatments were identical to those in Experiment 1, except that the door to each sound-attenuation chamber remained open to allow observation of each rat's behavior during the stress session.

An experimenter made a discrete observation of each rat's behavior in each of the shocked groups at the onset of shock on each trial and every $6 \mathrm{sec}$ thereafter until the trial terminated. Behavior also was scored every $15 \mathrm{sec}$ during the interval between shocks in Groups D-IS and I-IS. Observations for each rat in the no-shock control group were yoked to a rat in one of the two shocked groups so that observations for one half of the rats in Group C-NS occurred at times that observations were made for rats in Group D-IS; observations for the other rats in Group C-NS were made at the same times that scores were taken for rats in Group I-IS. For all rats, behavioral observations were sorted into one of two mutually exclusive categories (cf. Fanselow, 1982, Experiment 4; Mineka, Cook, \& Miller, 1984, Experiments 3 and 4): (1) freezing, which was defined as the absence of skeletal movement except for that due to respiration or minimal vibrissae movement; and (2) other, which was defined as all behavior other than freezing. Another experimenter also rated behavior in a pilot study, and interrater reliability showed $97.5 \%$ agreement.

The fear test commenced on Day 3 and was conducted over two consecutive daily sessions. Before each fear test, a rat that was not participating in the experiment received five shocks in the grid-floor compartment of the test apparatus to ensure that rat stress-odors were present (cf. Minor, 1990; Minor \& LoLordo, 1984). We then

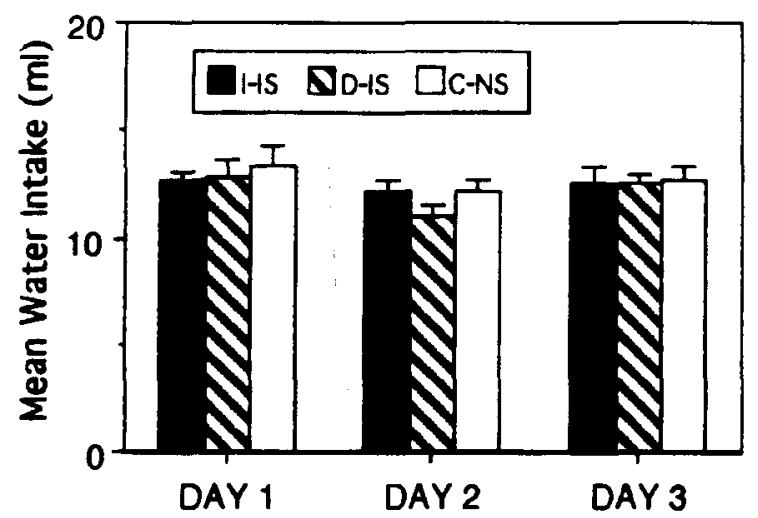

Figure 3. Mean absolute water consumption during drinking sessions of Test Days 1, 2, and 3 at $1600 \mathrm{~h}$ in the increasing-shockduration order group (I-IS), the decreasing-shock-duration order group (D-IS), and the no-shock control group (C-NS). 
placed an experimental subject on the safety platform in the test apparatus for $15 \mathrm{~min}$. Thereafter, the door between compartments was opened to allow a $15-\mathrm{min}$ access to the grid floor in the other compartment of the chamber. The light and fan were both operating, and the door to the attenuation chamber was open, as in the shock session. An experimenter, who was blind to the rats' stress condition, recorded the total amount of time spent on the grid floor during the second $15 \mathrm{~min}$ of the session. Grid-floor time was defined as the time when both rear paws were on the grid (cf. Mineka et al., 1984; Rosellini et al., 1986).

\section{Results}

Stress session. The percentage of intertrial intervals (ITIs) in which freezing was observed across blocks of 10 trials during the stress session is shown in Figure 4 for each of the three groups. Both shocked groups (D-IS and I-IS) showed similar levels of freezing throughout the session, which was considerably higher than that occurring in the noshock control (C-NS). Nonparametric analysis (chi-square) was conducted to compare the control group with the other two groups in amount of freezing, because there was virtually no freezing (and, hence, no variance in the distribution of scores) in the control group. This analysis revealed that the control group differed significantly from the other two groups in amount of freezing $\left[\chi^{2}(1)=23.694, p<.001\right]$. There was sufficient variance in the distribution of freezing scores in the two shocked groups for a parameteric analysis. A mixed-design ANOVA (group $\times$ trial block) on percent freezing in Groups D-IS and I-IS yielded a significant main effect of trial block $[F(10,220)=2.17, p=.021]$, which reflects the increase in freezing over trials; however, neither the main effect of group nor the group $\times$ trial block interaction was statistically significant $(F \mathrm{~s}<1)$.

Freezing during the ITIs in blocks of 10 trials was subjected to linear, quadratic, cubic, and fourth-power trend analyses to assess whether the form of the freezing functions differed in Groups I-IS and D-IS (Hays, 1963). Each type of transformation yielded a single score for each subject. Separate one-way ANOVAs were then used to com-

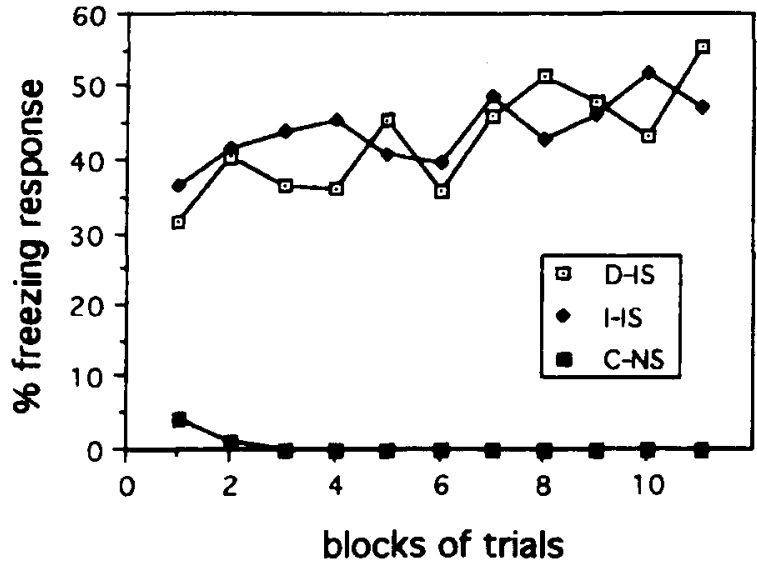

Figure 4. Mean percent freezing behavior during the interval between shock trials for rats exposed to a series of increasing inescapable-shock durations (I-IS), a series of decreasing shock durations (D-IS), or no shock (C-NS). Data are presented in blocks of 10 trials. pare the two groups for each type of transformation. There were no significant differences between groups in any of the four trend analyses (all $F \mathrm{~S}<1$ ). Thus, there was no evidence for a difference in freezing behavior across the ITIs in the D-IS and I-IS groups.

Figure 5 shows the mean percentage of intervals in which freezing was observed during shock in Groups I-IS and D-IS, or in yoked time intervals in Group C-NS, in each block of 10 trials. A nonparametric (chi-square) analysis showed that the control group differed significantly from the inescapable-shock groups in amount of freezing during shock $\left[\chi^{2}(1)=20.045, p<.001\right]$. A mixed-design ANOVA (group $\times$ trial block) conducted on data for only Groups I-IS and D-IS did not yield a main effect of group $(F<1)$ or of trial block $[F(10,220)=1.50, p>.05]$, nor a significant group $\times$ trial block interaction $(F<1)$. Analyses of linear, quadratic, cubic, and fourth-power trends in the acquisition of freezing during shock failed to identify any significant differences between the two shocked groups $(F \mathrm{~s}<1.86, p \mathrm{~s}>.17)$. Thus, Groups I-IS and D-IS did not differ in either the overall amount of freezing or the form of the acquisition function for freezing during shock.

Fear test. The distributions of scores for the total time spent on the grid floor during the test in each group were dramatically skewed with a flat kurtosis, thus precluding a parametric analysis. Therefore, fear of the grid floor and chamber during the 2 test days was assessed in terms of the number of subjects in each group that remained on the safety platform, as is shown in Figure 6. Fear was greatest during the test in the group that had received the increasing order of shock duration $24 \mathrm{~h}$ earlier: On Day 1 of the test, 7 of 12 rats in Group I-IS and 3 of 12 rats in Group D-IS did not spend any time on the grid floor; all rats in Group C-NS spent at least some time on the grid floor. On Day 2, fear of the grid floor decreased in both shocked groups, with 4 rats in Group I-IS but only 1 rat in Group DIS failing to leave the safety platform.

Fisher exact probability tests were used to assess data from the test. On Day 1, a greater proportion of the subjects in Group I-IS remained on the safety platform than of those in Group D-IS ( $p=.018)$. There was no significant difference between Group D-IS and the no-shock control group ( $p=.091)$. Moreover, a post hoc comparison revealed that there was a significant difference between Group I-IS and Group C-NS $(p=.018)$. On Day 2, there was no significant difference between Groups I-IS and D-IS ( $p=.232$ ) or between the decreasing duration order group and the no-shock control group $(p=.091)$. However, a post hoc contrast indicated that the significant difference between Groups I-IS and C-NS remained ( $p=$ .018 ), leaving some question as to the actual ordering of groups on the second day of testing.

\section{Discussion}

The results of this experiment are contrary to the response-competition explanation of the shock-duration order effect offered by Balleine and Job (1991). According to this account, freezing during shock and the ITI should have been greatest in the group exposed to the decreasing 


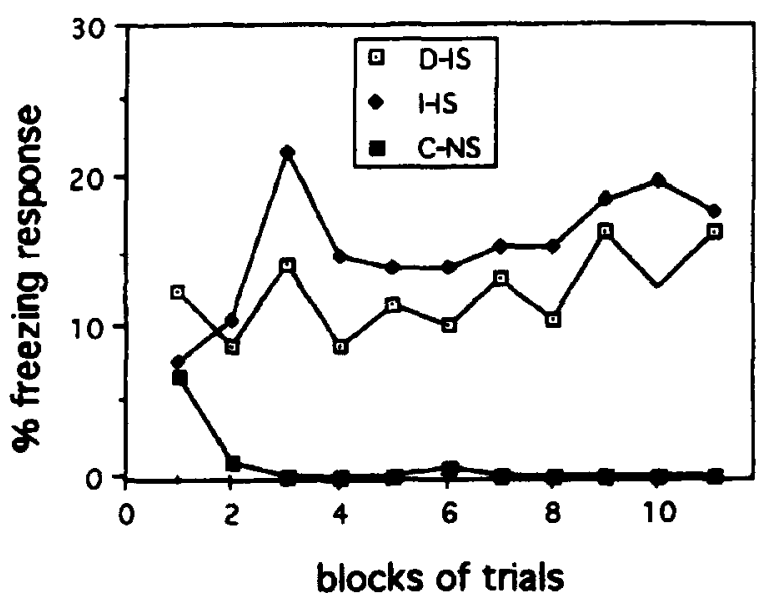

Figure 5. Mean percent freezing during shock in blocks of 10 trials for rats exposed to a series of increasing inescapable-shock durations (I-IS), a series of decreasing shock durations (D-IS), or no shock (C-NS).

series of shock durations (D-IS), particularly toward the end of training. However, Groups I-IS and D-IS did not differ in overall levels of, or in linear trend in, freezing across trials. This failure to identify group differences during pretreatment is unlikely to have been an artifact of ceiling levels of freezing in the two groups, given that freezing did not approach $100 \%$ in either group.

The greater conditioned fear of the pretreatment apparatus shown by Group I-IS during the test phase of the experiment is highly surprising, given that Groups I-IS and D-IS did not show differential fear during the pretreatment acquisition phase. Importantly, this outcome is completely at odds with fear-based explanations of helplessness phenomena (Mineka et al., 1984; Minor, Dess, \& Overmier, 1991; Weiss \& Simson, 1985). According to such accounts, evidence of distress and helplessness is assumed to be directly related to the amount of fear experienced during pretreatment and expressed at the beginning of testing. Contrary to this view are the findings that rats exposed to a series of decreasing shock durations do not show greater pretreatment fear than do those exposed to the increasing series, but do show greater impairment of test escape latencies (Balleine \& Job, 1991) and evidence of finickiness (Experiment 1), while showing less conditioned fear at the time of testing relative to the I-IS condition.

\section{GENERAL DISCUSSION}

The present experiments show that the effects of shockduration order on later test performance are not limited to escape behavior (Balleine \& Job, 1991). Shock-duration order also influences the consumption of quinine-adulterated water or "finickiness" (Experiment 1) and conditioned contextual fear (Experiment 2). Furthermore, the results of these experiments indicate a dissociation of effects. Whereas the increasing duration order provided prophylaxis against the finickiness effect, it resulted in more conditioned contextual fear than did the decreasing duration order.
The similarity between the shock groups in terms of freezing and therefore fear (Fanselow, 1986; Maier, 1990; Minor et al., 1991) at the time of the stress session, followed by clear differences in fear the next day, suggests that the latter difference arose from differential conditioning of the fear. The results of Experiment 2 indicated that during the stress session the amount of freezing during the ITI of the inescapably shocked groups was not significantly different between the groups. Given that freezing is a measure of fear that is accepted by anxiety hypothesis proponents (Minor et al., 1991), these data suggest that the level of anxiety was similar in the two shock groups during shock treatment. The fear test, however, showed that the increasingduration-order group exhibited greater conditioned fear to the context than did the decreasing-duration-order group on the 1 st test day.

This apparent dissociation of effects due to a manipulation of the order of inescapable shock durations is not explicable in terms of any of the current theories of the helplessness effect. Learned helplessness theory does not predict that the order of shock durations of inescapable shock, which is an artifact of the yoking procedure, should have any effect on the helplessness effect. The learned helplessness theory could account for the basic finickiness effect if the emotional deficit is assumed to include ingestive problems, but could not account for the prophylactic effect of increasing order of durations. Furthermore, the theory does not predict differences in fear conditioned to the pretreatment context for decreasing-order-duration and increasing-order-duration groups. Similarly, other cognitive or attentional theories (Barber, Mortimer, \& Winefield, 1992; Lee \& Maier, 1988) allow no role for the order of uncontrollable events.

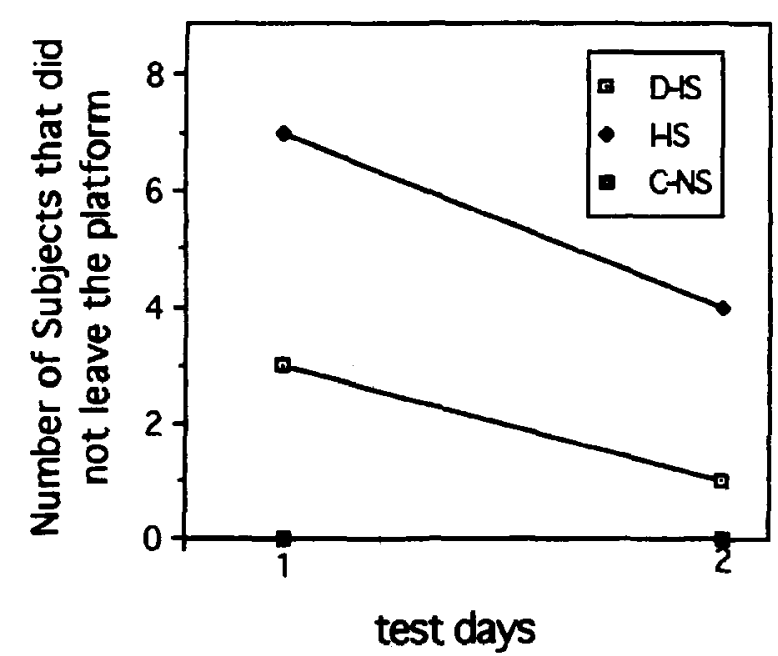

Figure 6. Number of rats in each of three groups that did not leave the safety platform during the test of fear of the shock apparatus, 24 and $48 \mathrm{~h}$ after the shock session. Rats were exposed to a session of increasing shock-duration order inescapable shocks (I-IS), decreasing shock-duration order inescapable shocks (D-IS), or no shocks (C-NS). Rats were given a choice of remaining on the safety platform or approaching the grid floor of the shock chamber. 
Balleine and Job's $(1988,1991)$ earlier research suggested that a revised response-competition hypothesis (Anisman \& Waller, 1973; Bracewell \& Black, 1974; Glazer \& Weiss, 1976a, 1976b; Levis, 1976) might provide an account for the shock-duration order effect in terms of the response that is reinforced during pretreatment. The present experiments, however, identify a number of problems for this type of explanation. First, the hypothesis cannot deal with an effect of shock-duration order on a low-activity test measure like quinine finickiness (Experiment 1). Second, the groups did not show the predicted differences in freezing during pretreatment (Experiment 2). Finally, the increasing-shock-duration order condition produced more fear of the context (Experiment 2), an outcome that is inconsistent with the instrumental learning mechanism offered by Balleine and Job (1991).

The anxiety hypothesis does not predict an effect of shock-duration order on test performance. However, this type of hypothesis could accommodate the findings of differentially impaired escape performance (Balleine \& Job, 1991) and bitter-taste finickiness (Experiment 1), if it were the case that the decreasing duration order group experienced greater pretreatment and test fear than did the increasing-duration-order group. Under these conditions, evidence of greater distress and helplessness following D-IS treatment could be attributed to the associative and nonassociative consequences of greater pretreatment fear, although the mechanism responsible for differential fearfulness among D-IS and I-IS rats would remain unstated. This modifed anxiety account was directly tested and falsified in Experiment 2. Indeed, the order of the two inescapably shocked groups in conditioned fear to the pretreatment apparatus was directly opposite to the prediction.

Despite these problems with a fear-based interpretation, it still may be possible to account for shock-durationorder effects in terms of the specificity (rather than the amount) of fear conditioning to environmental cues during exposure to inescapable shock. An increasing series of shock durations may produce a conditioned fear that is very specific to the pretreatment context. This highly specific form of conditioning would account for the greater conditioned fear to the pretreatment context that was shown by I-IS rats in Experiment 2. At the same time, however, less fear should generalize to other test contexts following I-IS treatment. This outcome should be especially true when testing occurs in the home cage, as in the finickiness test of Experiment 1, and also may be true when testing occurs in a shuttle box (e.g., Balleine \& Job, 1991) because of differences in contexts between the pretreatment and test phases of the experiments. This failure of fear to generalize across experimental contexts should alleviate symptoms of distress and helplessness in the test phase, according to several current conceptions (cf. Mineka et al., 1984; Minor \& LoLordo, 1984; Weiss \& Simson, 1985).

By contrast, a series of decreasing inescapable-shock durations may result in a "free-floating" fear, a chronic state of anxiety that is not associated strongly with a particular situation. This type of fear may be analogous to gen- eralized anxiety disorder (American Psychiatric Association, 1987). A "free-floating" anxiety should persist over many different contexts and situations. This proposal has its roots in Denny's analysis of shock effects in terms of punishment by one shock of the relaxation response occurring after the preceding shock resulting in free-floating or pervasive anxiety (Denny, 1976; Denny \& Dmitruk, 1967). On the present account, during a test in a different context the D-IS group would experience a general anxiety, resulting in the helplessness effect. This suggestion is worthy of further investigation, not only because it is able to account for an otherwise perplexing dissociation of the effects of shock-duration order, but also because of its potential practical implications. This account may offer greater understanding of the reasons for uncontrollable stress on some occasions leading to helplessness and depression (Seligman, 1975, 1991), and on other occasions leading to phobias (Wolpe, 1969).

\section{REFERENCES}

American Psychiatric Assoclation (1987). Diagnostic and statistical manual of mental disorders (3rd ed. rev.). Washington, DC: Author.

Anderson, C., Crowell, C. R., Cunningham, C. L., \& Lupo, J, V. (1979). Behavior during shock exposure as a determinant of subsequent interference with shuttle box escape-avoidance learning in the rat. Journal of Experimental Psychology: Animal Behavior Processes, 5, 243-257.

Anisman, H., deCatanzaro, D., \& Remington, G. (1978). Escape performance deficits following exposure to inescapable shock: Deficits in motor response maintenance. Journal of Experimental Psychology: Animal Behavior Processes, 4, 197-218.

ANISMaN, H., \& WaLLER, T. G. (1973). Effects of inescapable shock on subsequent avoidance performance: Role of response repertoire changes. Behavioural Biology, 9, 331-355.

Balleine, B., \& JOB, R. F. S. (1988, August). The differential effects of partial and continuous reinforcement on the interference effect in rats. Paper presented at the 24th International Congress of Psychology, Sydney.

BalleINe, B., \& JoB, R. F. S. (1991). Reconsideration of the role of competing responses in demonstrations of the interference effect (learned helplessness). Journal of Experimental Psychology: Animal Behavior Processes, 17, 270-280.

Barber, J. G., Mortimer, J., \& Winefield, A. H. (1992). Helplessness deficits: Effects of amount of pretraining and test task difficulty. Australian Journal of Psychology, 44, 61-64.

Berger, D. F., Starzec, J. J., Mason, E. B., \& Devito, W. (1980). The effects of differential psychological stress on plasma cholesterol levels in rats. Psychosomatic Medicine, 42, 481-492.

Bracewell, R. J., \& BlaCK, A. H. (1974). The effects of restraint and noncontingent preshock on subsequent escape learning in the rat. Learning \& Motivation, 5, 53-69.

Brennan, F. X., Job, R. F. S., Watkins, L. R., \& MaIER, S. F. (1992). Total plasma cholesterol levels of rats are increased following only three sessions of tailshock. Life Sciences, 50, 945-950.

Brown, G. E., \& Dixon, P. A. (1983). Learned helplessness in the gerbil. Journal of Comparative Psychology, 97, 90-92.

Brush, F. R., Del Paine, S. N., Pellegrino, L. J., Rykaszewski, I. M., Dess, N. K., \& Collins, P. Y. (1988). CER suppression, passive avoidance learning and stress induced suppression of drinking in the Syracuse high and low avoidance strains of rats (Rattus norvegicus). Journal of Comparative Psychology, 4, 337-349.

Crowell, C. R., \& Anderson, D. C. (1979). Shuttle interference effects in the rat depend upon activity during prior shock: A replication. Bulletin of the Psychonomic Society, 14, 413-416.

Crowell, C. R., Lupo, J. V., Cunningham, D. L., \& Anderson, D. C. (1978). Temporal form of shock is a determinant of magnitude of in- 
terference with escape-avoidance learning produced by exposure to inescapable shock. Bulletin of the Psychonomic Society, 12, 407-410.

DenNy, M. R. (1976). Post-aversive relief and relaxation and their implications for behavior therapy. Journal of Behavior Therapy \& Experimental Psychiatry, 7, 315-321.

DENNY, M. R., \& DMITRUK, V. M. (1967). Effects of punishing a single failure to avoid. Journal of Comparative \& Physiological Psychology, 63, 277-281.

Dess, N. K. (1991). Ingestion and emotional health. Human Nature, 2 , 235-269.

DEss, N. K., \& ChapMAN, C. D. (1990). Individual differences in taste, body weight, and depression in the "helplessness" rat model and in humans. Brain Research Bulletin, 24, 669-676.

Dess, N. K., Chapman, C. D., \& Minor, T. R. (1988). Inescapable shock increases finickiness about drinking quinine-adulterated water in rats. Learning \& Motivation, 19, 408-424.

Dess, N. K., Raizer, J., Chapman, C. D., \& Garcia, J. (1988). Stressors in the learned helplessness paradigm: Effects on body weight and conditioned taste aversion in rats. Physiology \& Behavior, 44, 483-490.

FANSElow, M. S. (1982). The postshock activity burst. Animal Learning \& Behavior, 10, 448-454.

FANSELOW, M. S. (1986). Associative vs topographical accounts of the immediate shock-freezing deficit in rats: Implications for the response selection rules governing species-specific defensive reactions. Learning \& Motivation, 17, 16-39.

Garrick, T., MinoR, T. R., BaUCK, S., WeInER, H., \& GUTH, P. (1989). Predictable and unpredictable shock stimulates gastric contractility and causes mucosal injury in rats. Behavioral Neuroscience, 103, 124-130.

GlAZER, H. I., \& WEISS, J. M. (1976a). Long-term and transitory interference effects. Journal of Experimental Psychology: Animal Behavior Processes, 2, 191-201.

Glazer, H. I., \& WeISs, J. M. (1976b). Long-term interference effect: An alternative to "learned helplessness." Journal of Experimental Psychology: Animal Behavior Processes, 2, 202-213.

Jackson, R. L., MaIER, S. F., \& RAPAPORT, P. M. (1978). Exposure to inescapable shock produces both activity and associative deficits in the rat. Learning \& Motivation, 9, 69-98.

JACKSON, R. L., \& MINOR, T. R. (1988). Effects of signaling inescapable shock on subsequent escape learning: Implications for theories of coping and "learned helplessness." Journal of Experimental Psychology: Animal Behavior Processes, 14, 390-400.

JOB, R. F. S. (1987). Learned helplessness in chickens. Animal Learning \& Behavior, 15, 347-350

JoB, R. F. S., \& BARNES, B. W. (1995). Stress and consumption: Inescapable shock, neophobia and finickiness about drinking quinineadulterated water. Behavioral Neuroscience, 109, 106-116.

KELSEY, J. E. (1971). Escape acquisition following inescapable shock in the rat. Animal Learning \& Behavior, 5, 83-92.

LEE, R. K., \& MAIER, S. F. (1988). Inescapable shock and attention to internal versus external cues in a water discrimination escape task. Journal of Experimental Psychology: Animal Behavior Processes, 14, 302-310.

LEVIS, D. J. (1976). Learned helplessness: A reply and an alternative S-R interpretation. Journal of Experimental Psychology: General, 105, 47-65.

MAIER, S. F. (1970). Failure to escape traumatic electric shock: Incompatible skeletal-motor responses or learned helplessness? Learning \& Motivation, 1, 157-169.

MAIER, S. F. (1990). Role of fear in mediating shuttle escape learning deficit produced by inescapable shock. Journal of Experimental Psychology: Animal Behavior Processes, 16, 137-149.

MineKa, S., CoOK, M., \& Miller, S. (1984). Fear conditioned with escapable and inescapable shock: Effects of a feedback stimulus. Journal of Experimental Psychology: Animal Behavior Processes, 10, 307-323.
MinoR, T. R. (1990). Conditioned fear and neophobia following inescapable shock. Animal Learning \& Behavior, 18, 212-226.

Minor, T. R., Dess, N. K., \& OVERMIER, J. B. (1991). Inverting the traditional view of "learned helplessness": A reinterpretation in terms of anxiety and modulator operations. In M. R. Denny (Ed.), Aversive events and behavior (pp. 87-133). Hillsdale, NJ: Erlbaum.

MinOR, T. R., \& LoLordo, V. M. (1984). Escape deficits following inescapable shock: The role of contextual odor. Journal of Experimental Psychology: Animal Behavior Processes, 10, 168-181.

Minor, T. R., Trauner, M. A., Lee, C. Y., \& Dess, N. K. (1990). Modelling signal features of escape response: Effects of cessation conditioning in "learned helplessness" paradigm. Journal of Experimental Psychology: Animal Behavior Processes, 16, 123-136.

Nation, J. R., \& MathenY, J. L. (1980). Instrumental escape after responding after passive avoidance training: Support for an incompatible response account of learned helplessness. American Journal of Psychology, 93, 299-308.

OVermier, J. B., \& Murison, R. (1989). Post-stress effects of danger and safety signals on gastric ulcerations. Behavioral Neuroscience, 103, 1296-1301.

Overmier, J. B., \& Seligman, M. E. P. (1967). Effects of inescapable shock on subsequent escape and avoidance learning. Journal of Comparative \& Physiological Psychology, 86, 101-106.

PRabhaKar, T., \& Job, R. F. S. (1994). The shock duration order effect and the finickiness effect. Australian Journal of Psychology, 46, 25.

Rosellini, R. A., DeCola, J. P., Plonsky, M., Warren, D. A., \& Stillman, A. J. (1984). Uncontrollable shock proactively increases sensitivity to response-reinforcer independence in rats. Journal of Experimental Psychology: Animal Behavior Processes, 10, 346-359.

Rosellini, R. A., DeCola, J. P., \& WarRen, D. A. (1986). The effect of feedback stimuli on contextual fear depends upon the length of the minimum intertrial interval. Learning \& Motivation, 17, 229-242.

Rosellini, R. A., \& SEligman, M. E. P. (1978). Role of shock intensity in the learned helplessness paradigm. Animal Learning \& Behavior, 6, 143-146.

Seligman, M. E. P. (1975). Helplessness: On depression development and death. New York: W. H. Freeman.

Seligman, M. E. P. (1991). Learned optimism. Milson's Point, NSW: Random House Australia.

Steenbergen, H. L., Hėinsbroek, R. P., Van HaAren, F., \& Van DE POLL, N. E. (1989). Sex-dependent effects of inescapable shock administration on behavior and subsequent escape performance in rats. Physiology \& Behavior, 45, 781-787.

Warren, D. A., Rosellini, R. A., \& Plonsky, M. (1985). Regularity of inescapable shock duration affects behavioral topography, but not shuttle escape performance. Psychological Record, 35, 227-238.

WEISs, J. M. (1968). Effects of coping responses on stress. Journal of Comparative \& Physiological Psychology, 65, 251-260.

WEISs, J. M. (1971a). Effects of coping behavior in different warning signal conditions on stress pathology in rats. Journal of Comparative \& Physiological Psychology, 77, 1-13.

WEISS, J. M. (1971b). Effects of punishing the coping response (conflict) on stress pathology in rats. Journal of Comparative \& Physiological Psychology, 77, 14-21.

WEISS, J. M. (1971 c). Effects of coping behavior with and without a feedback signal on stress pathology in rats. Journal of Comparative \& Physiological Psychology, 77, 22-30.

WeIss, J. M., \& Simson, P. G. (1985). Neurochemical mechanisms underlying stress induced development. In T. Field, P. McCabe, \& N. Schneiderman (Eds.). Stress and coping (pp. 93-108). Hillsdale, NJ: Erlbaum. WOLPE, J. (1969). The practice of behavior therapy. New York: Pergamon.

(Manuscript received January 10, 1994; revision accepted for publication May 31, 1994.) 